\title{
Pharmacokinetic Modelling of Lamotrigine from Plasma Concentrations in Healthy Volunteers
}

\author{
Ilbeyi Agabeyoglu*, Tuba Incecayir
}

Dept.Pharmaceutical Technology, Faculty of Pharmacy, Gazi University, Ankara, TURKEY

\begin{abstract}
The pharmacokinetics of the antiepileptic agent lamotrigine (CAS 84057-84-1) was investigated after single oral doses in 14 healthy volunteers. After the administration of single oral doses of $2 \times 100 \mathrm{mg}$ lamotrigine chewable/soluble tablets to healthy volunteers, blood samples were collected for the next $96 \mathrm{~h}$. The pharmacokinetic modelling of lamotrigine showed that the drug exhibited two compartment open model with regard to the goodness of fits, Residual Sum of Squares (RSS), Akaike's Information Criteria (AIC), Schwartz Criteria (SC), standard deviation of the regression $(\mathrm{Sr})$, and determination coefficient $\left(\mathrm{r}^{2}\right)$. The time-concentration curves showed a mean time to reach peak plasma concentration, $\mathrm{C}_{\max }\left(\mathrm{t}_{\max }\right)$ of $2.0 \mathrm{~h}$. The pharmacokinetic parameters were calculated based on the plasma curves. Area under the curve of concentration versus time from zero to infinity $(A U C)$, systemic clearance $(\mathrm{Cl})$, apparent volume of distribution $\left(\mathrm{V}_{\text {darea }}\right)$, apparent volume of distribution at steady state $\left(\mathrm{V}_{\mathrm{dss}}\right)$, apparent volume of distribution for I.V. $\left(\mathrm{V}_{\text {dext }}\right)$, and mean residence time (MRT) were found to be $128 \pm 31 \mu \mathrm{g} . \mathrm{h} /$ $\mathrm{mL}, 1.63 \pm 0.39 \mathrm{~L} / \mathrm{h}, 88.5 \pm 28.6 \mathrm{~L}, 83.2 \pm 23.6 \mathrm{~L}, 93.2 \pm 35.6$ $\mathrm{L}$, and $62.6 \pm 13.7 \mathrm{~h}($ mean $\pm \mathrm{SD})$, respectively. Compartmental analysis demonstrated that oral lamotrigine tablets obey two compartment open model with rapid absorption and a relatively long half life.
\end{abstract}

Keywords: Lamotrigine; Pharmacokinetics; Modelling

\section{Introduction}

Being a member of the phenyltriazine class, lamotrigine (6(2, 3-dichlorophenyl)-1, 2, 4-triazine-3, 5-diamine, CAS 84057 84-1) is an anticonvulsant, that has a novel chemical structure and mechanism of action (Goa et al., 1993). It exerts its antiepileptic effects by blocking the voltage-sensitive sodium channels and inhibiting the release of glutamate (LaRoche, 2007; Stefan et al., 2007). Lamotrigine exhibits a broad spectrum of efficacy, being active against partial seizures with or without secondary generalization, primarily generalized tonic-clonic seizures, absence seizures, and drop attacks associated with the Lennox-Gastaut Syndrome (Perucca, 1996; Frank et al., 1999; Motte et al., 1997). The present study is designed to carry out the pharmacokinetic modelling of lamotrigine in plasma after the administration of a single oral dose to 14 healthy volunteers.

\section{Materials and Methods}

\section{Clinical protocol}

The study was an open-label, single period, single-dose study. 14 healthy volunteers, nine males and five females within $10 \%$ of their ideal body weight participated in the study. Their mean age was $23 \pm 2$ years. After the administration of single oral doses of $2 \times 100 \mathrm{mg}$ lamotrigine chewable/soluble tablets (LAMICTAL $^{\text {TM }}$ DC $100 \mathrm{mg}$ chewable/soluble tablets, GlaxoWellcome, Istanbul, Turkey, batch no. B117131) to volunteers, blood samples were collected at $0,0.25,0.5,1,2,4,6$, $8,10,12,24,48,72$ and $96 \mathrm{~h}$. Study design and drug analysis details can be found in the previous paper by the authors (Incecayir et al., 2007).

\section{Data analysis}

Most of the plasma concentration data were modelled by the program KINETICA ${ }^{\mathrm{TM}}$ (Version 3.1; Philadelphia, USA). Some of the data were stripped with the programme ESTRIP (Brown et al., 1978), while two were fit manually (Wagner, 1979). Both ESTRIP and manual fits were further optimized by nonlinear regression, using the program SPSS v.11.5.

The mean time to reach peak plasma concentration, $\mathrm{C}_{\text {max }},\left(\mathrm{t}_{\text {max }}\right)$ for a three exponential function cannot be determined directly, as for a two exponential model. Iterative techniques as described by Wagner, (1979) has been employed for this purpose for each subject equation. $\mathrm{C}_{\max }$ 's have then been calculated by substitution in the respective equations.

\section{Results}

The semilogarithmic mean plasma concentration-time profile of lamotrigine during $96 \mathrm{~h}$. in 14 healthy volunteers are shown in Figure 1.

The data were fit both to one compartment and two compartment open models. The equations describing the compartments are as follows:

$$
\begin{aligned}
& C_{p}=C_{1} e^{-k_{d} t}+C_{2} e^{-k_{a} t} \quad \text { One comp. model } \\
& C_{p}=C_{1} e^{-\alpha t}+C_{2} e^{-\beta t}+C_{3} e^{-k_{a} t} \quad \text { Two comp. model }
\end{aligned}
$$

where, $\mathrm{C}_{\mathrm{p}}$ is the plasma concentration $(\mu \mathrm{g} / \mathrm{mL}) ; \mathrm{k}_{\mathrm{d}}, \beta$, disposition rate constants $\left(\mathrm{h}^{-1}\right) ; \mathrm{k}_{\mathrm{a}}$, absorption rate constant $\left(\mathrm{h}^{-1}\right) ; \alpha$, distribution rate constant $\left(\mathrm{h}^{-1}\right)$; and $\mathrm{C}_{\mathrm{i}}$ 's, coefficients $(\mu \mathrm{g} / \mathrm{mL}) . \alpha, \beta$, $\mathrm{C}_{1}, \mathrm{C}_{2}$ and $\mathrm{C}_{3}$ are the macrorate constants. Obtained macro pa-

*Corresponding author: Prof.Dr.llbeyi Agabeyoglu, Gazi Univ. Ecz. Fak. Etiler 06330 Ankara/TURKEY, Tel: +90 (532) 26299 39; Fax: +90 (312) 21279 58; E-mail: ilbeyi@tr.net

Received December 06, 2009; Accepted December 28, 2009; Published December 28, 2009

Citation: Agabeyoglu I, Incecayir T (2009) Pharmacokinetic Modelling of Lamotrigine from Plasma Concentrations in Healthy Volunteers. J Bioanal Biomed 1: 041-045. doi:10.4172/1948-593X.1000009

Copyright: (c) 2009 Agabeyoglu I, et al. This is an open-access article distributed under the terms of the Creative Commons Attribution License, which permits unrestricted use, distribution, and reproduction in any medium, provided the original author and source are credited.

J Bioanal Biomed 
Citation: Agabeyoglu I, Incecayir T (2009) Pharmacokinetic Modelling of Lamotrigine from Plasma Concentrations in Healthy Volunteers. J Bioanal Biomed 1: 041-045. doi:10.4172/1948-593X.1000009

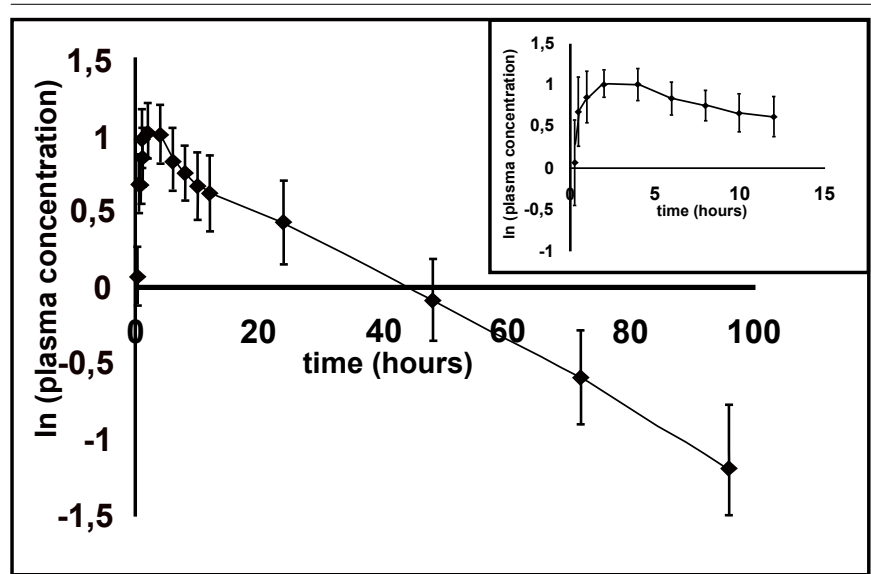

Figure 1: Semilogarithmic mean plasma concentration-time profiles of lamotrigine in 14 healthy volunteers(with standard deviations).

\begin{tabular}{|l|l|l|l|l|}
\hline SUBJECT & $\mathbf{C}_{\mathbf{1}}(\boldsymbol{\mu g} / \mathbf{m L})^{\mathbf{a}}$ & $\mathbf{C}_{\mathbf{2}}(\boldsymbol{\mu g} / \mathbf{m L})^{\mathbf{b}}$ & $\mathbf{k}_{\mathbf{d}}\left(\mathbf{h}^{-\mathbf{1}}\right)^{\mathbf{c}}$ & $\mathbf{K}_{\mathbf{a}}\left(\mathbf{h}^{-\mathbf{1}}\right)^{\mathbf{d}}$ \\
\hline $\mathbf{1}$ & 2.95 & -2.95 & 0.0196 & 2.28 \\
\hline $\mathbf{2}$ & 2.39 & -2.39 & 0.0244 & 2.54 \\
\hline $\mathbf{3}$ & 3.78 & -3.78 & 0.0268 & 2.11 \\
\hline $\mathbf{4}$ & 2.58 & -2.58 & 0.0230 & 1.24 \\
\hline $\mathbf{5}$ & 2.71 & -2.71 & 0.0295 & 3.54 \\
\hline $\mathbf{6}$ & 2.53 & -2.53 & 0.0664 & 2.14 \\
\hline $\mathbf{7}$ & 3.75 & -3.75 & 0.0328 & 4.51 \\
\hline $\mathbf{8}$ & 2.76 & -2.76 & 0.0178 & 3.00 \\
\hline $\mathbf{9}$ & 2.60 & -2.60 & 0.0188 & 0.694 \\
\hline $\mathbf{1 0}$ & 2.54 & -2.54 & 0.0190 & 3.83 \\
\hline $\mathbf{1 1}$ & 2.80 & -2.80 & 0.0260 & 1.58 \\
\hline $\mathbf{1 2}$ & 3.41 & -3.41 & 0.0231 & 2.54 \\
\hline $\mathbf{1 3}$ & 2.62 & -2.62 & 0.0298 & 5.13 \\
\hline $\mathbf{1 4}$ & 2.75 & -2.75 & 0.0343 & 5.06 \\
\hline $\mathbf{M e a n}^{\mathbf{e}}$ & 2.87 & -2.87 & 0.0279 & 2.87 \\
\hline SD & 0.45 & 0.45 & 0.0123 & 1.38 \\
\hline $\mathbf{C V}^{\mathbf{f}}$ & 15.7 & -15.7 & 43.9 & 48.0 \\
\hline
\end{tabular}

a, bmacrorate constants; ' ${ }^{\mathrm{d}}$ isposition rate constants $\left(\mathrm{h}^{-1}\right)$; ${ }^{\mathrm{d}}$ absorption rate const. $\left(\mathrm{h}^{-1}\right)$; ${ }^{\mathrm{e}}$ Standard deviation; ${ }^{\mathrm{f}}$ Coefficient of variation.

Table 1: One compartment macroparameters. tion coefficient $\left(r^{2}\right)$. Fits for one and two compartment models are given in Tables 3 and 4 .

Microrate constants calculated from two compartment model are given in Table 5 and other pharmacokinetic parameters in Table 6.

\section{Discussion}

In pharmacokinetic data analysis, it is necessary to select the correct model, allowing estimation of pharmacokinetic parameters with small bias and good precision, and to select a model, allowing precise predictions of concentrations. Therefore, the present study was designed to carry out plasma pharmacokinetics of lamotrigine in 14 healthy volunteers after the administration of single oral doses of $200 \mathrm{mg}$. In our previous paper (Incecayir et al., 2007), only noncompartmental approach was employed to data, whereas full pharmacokinetic modelling is employed in this paper. It was seen that two compartment fits gave better results than one compartment fits with regard to all five criteria, RSS, AIC, SC, Sr and $\mathrm{r}^{2}$ (Figure 2). From Figure 1, which is a semilogarithmic plot, the two phase disposition is also apparent.

While some investigators (Yuen et al., 1987) declared that lamotrigine pharmacokinetics can be described by the one-compartment open model, the detailed statistical analysis conducted in this study with 14 volunteers' single dose data demonstrated that two compartmental open model was the correct pharmacokinetic model for lamotrigine. It is certainly known that lamotrigine is widely distributed to all organs and tissues, including brain tissue (Ramsay et al., 1991). In a study, a mean brain:serum ratio of 2.8 was found in 11 patients with brain tumors who had received lamotrigine $100-400 \mathrm{mg}$ /day from one day to 17 months (Goldsmith et al., 2003). Such a good distribution of lamotrigine in the brain is certainly a result of the basic and lipophilic properties of the molecule, which permits it to

\begin{tabular}{|c|c|c|c|c|c|c|}
\hline SUBJECT & $\mathrm{C}_{1}(\mu \mathrm{g} / \mathrm{mL})^{\mathrm{a}}$ & $\mathrm{C}_{2}(\mu \mathrm{g} / \mathrm{mL})^{\mathrm{b}}$ & $\mathrm{C}_{3}(\mu \mathrm{g} / \mathrm{mL})^{\mathrm{c}}$ & $\beta\left(h^{-1}\right)^{d}$ & $\alpha\left(h^{-1}\right)^{\mathbf{e}}$ & $k_{a}\left(h^{-1}\right)^{f}$ \\
\hline 1 & 2.06 & 49.2 & -51.3 & 0.0108 & 0.507 & 0.569 \\
\hline 2 & 2.30 & 9.85 & -12.2 & 0.0229 & 1.27 & 1.48 \\
\hline 3 & 2.91 & 0.952 & -3.86 & 0.0225 & 0.0557 & 2.03 \\
\hline 4 & 2.13 & 28.9 & -31.0 & 0.0176 & 0.481 & 0.534 \\
\hline 5 & 2.00 & 1.69 & -3.68 & 0.0182 & 0.280 & 2.36 \\
\hline 6 & 1.02 & 2.75 & -3.77 & 0.0135 & 0.243 & 1.32 \\
\hline 7 & 2.97 & 1.30 & -4.27 & 0.0239 & 0.194 & 3.45 \\
\hline 8 & 2.62 & 15.0 & -17.6 & 0.0161 & 1.32 & 1.55 \\
\hline 9 & 3.87 & -1.36 & -12.51 & 0.0231 & 0.0398 & 0.726 \\
\hline 10 & 2.24 & 0.476 & -2.71 & 0.0162 & 0.122 & 3.27 \\
\hline 11 & 2.60 & 22.1 & -24.7 & 0.0233 & 0.722 & 0.801 \\
\hline 12 & 3.04 & 1.14 & -4.18 & 0.0195 & 0.283 & 1.90 \\
\hline 13 & 1.87 & 1.01 & -2.88 & 0.0198 & 0.123 & 4.12 \\
\hline 14 & 1.46 & 1.42 & -2.89 & 0.0205 & 0.0707 & 4.41 \\
\hline Mean & 2.36 & 9.60 & -12.0 & 0.0191 & 0.408 & 2.04 \\
\hline SD $^{g}$ & 0.72 & 14.67 & -14.6 & 0.0040 & 0.423 & 1.31 \\
\hline $\mathrm{CV} \%^{\mathrm{h}}$ & 30.3 & 153 & 122 & 20.8 & 104 & 64.3 \\
\hline
\end{tabular}

a, b, cmacrorate constants; disposition rate constants $\left(\mathrm{h}^{-1}\right)$; ${ }^{\mathrm{e}}$ absorption rate const. $\left(\mathrm{h}^{-1}\right)$; ${ }^{\mathrm{f}}$ absorption rate const. $\left(\mathrm{h}^{-1}\right)$; ${ }^{\mathrm{g}}$ Standard deviation; ${ }^{\mathrm{h}} \mathrm{Coefficient}$ of variation.

Table 2: Two compartment macroparameters.

rameters for one and two compartment models are depicted in Tables 1 and 2 .

Goodness of fits were assessed with Residual Sum of Squares (RSS), Akaike's Information Criteria (AIC), Schwartz Criteria (SC), standard deviation of the regression ( $\mathrm{Sr}$ ) and determinaJ Bioanal Biomed cross the blood-brain barrier easily and have high affinity to the brain tissue (Castel-Branco et al., 2003). Also, a study (Garnett, 1997) assessed the ability of lamotrigine and its glucuronide metabolite to penetrate the blood-brain barrier in a 10 -year-old epileptic patient, who underwent a frontal topectomy to remove seizure-causing foci in the cerebral cortex, approximately four Volume 1(1) : 041-045 (2009) - 042 


\section{Journal of Bioanalysis \& Biomedicine - Open Access JBABM/Vol.1 Issue 1}

\begin{tabular}{|l|l|l|l|l|l|}
\hline SUBJECT & $\mathbf{R S S}^{\mathbf{a}}$ & $\mathbf{A I C}^{\mathbf{b}}$ & $\mathbf{S C}^{\mathbf{c}}$ & $\mathbf{S}_{\mathbf{r}}{ }^{\mathbf{d}}$ & $\mathbf{r}^{\mathbf{e}}$ \\
\hline $\mathbf{1}$ & 2.12 & 18.5 & 22.1 & 0.460 & 0.835 \\
\hline $\mathbf{2}$ & 0.375 & -5.73 & -3.17 & 0.194 & 0.956 \\
\hline $\mathbf{3}$ & 0.236 & 12.2 & -9.66 & 0.154 & 0.988 \\
\hline $\mathbf{4}$ & 0.450 & -3.19 & -0.636 & 0.212 & 0.950 \\
\hline $\mathbf{5}$ & 1.90 & 17.0 & 19.5 & 0.436 & 0.849 \\
\hline $\mathbf{6}$ & 0.656 & 2.11 & 4.66 & 0.256 & 0.906 \\
\hline $\mathbf{7}$ & 0.662 & 2.23 & 4.79 & 0.257 & 0.970 \\
\hline $\mathbf{8}$ & 0.757 & 4.10 & 6.65 & 0.275 & 0.931 \\
\hline $\mathbf{9}$ & 0.144 & -19.1 & -16.6 & 0.120 & 0.984 \\
\hline $\mathbf{1 0}$ & 0.221 & -13.1 & -10.6 & 0.149 & 0.975 \\
\hline $\mathbf{1 1}$ & 0.153 & -18.3 & -15.7 & 0.124 & 0.986 \\
\hline $\mathbf{1 2}$ & 0.603 & 0.918 & 3.47 & 0.246 & 0.964 \\
\hline $\mathbf{1 3}$ & 0.233 & -12.4 & -9.82 & 0.153 & 0.978 \\
\hline $\mathbf{1 4}$ & 0.315 & -8.17 & -5.61 & 0.178 & 0.974 \\
\hline $\mathbf{M e a n}^{\mathbf{f}}$ & 0.630 & -3.38 & -0.828 & 0.229 & 0.946 \\
\hline $\mathbf{S D}^{\mathbf{f}}$ & 0.620 & 11.71 & 11.71 & 0.106 & 0.050 \\
\hline
\end{tabular}

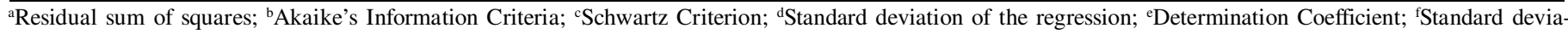
tion.

Table 3: One compartment fits.

\begin{tabular}{|l|l|l|l|l|l|}
\hline SUBJECT & $\mathbf{R S S}^{\mathbf{a}}$ & $\mathbf{A I C}^{\mathbf{b}}$ & $\mathbf{S C}^{\mathbf{c}}$ & $\mathbf{S}_{\mathbf{r}}{ }^{\mathbf{d}}$ & $\mathbf{r}^{\mathbf{2}}$ \\
\hline $\mathbf{1}$ & 0.601 & 4.87 & 8.70 & 0.274 & 0.953 \\
\hline $\mathbf{2}$ & 0.333 & -3.39 & 0.449 & 0.204 & 0.961 \\
\hline $\mathbf{3}$ & 0.225 & -8.90 & -5.06 & 0.168 & 0.989 \\
\hline $\mathbf{4}$ & 0.178 & -12.2 & -8.33 & 0.149 & 0.980 \\
\hline $\mathbf{5}$ & 1.31 & 15.8 & 19.6 & 0.405 & 0.896 \\
\hline $\mathbf{6}$ & 0.0431 & -32.0 & -28.2 & 0.0734 & 0.994 \\
\hline $\mathbf{7}$ & 0.369 & -1.97 & 1.86 & 0.215 & 0.983 \\
\hline $\mathbf{8}$ & 0.589 & 4.58 & 8.41 & 0.271 & 0.946 \\
\hline $\mathbf{9}$ & 0.138 & -15.7 & -11.9 & 0.132 & 0.984 \\
\hline $\mathbf{1 0}$ & 0.186 & -11.6 & -7.74 & 0.152 & 0.979 \\
\hline $\mathbf{1 1}$ & 0.0594 & -27.5 & -23.7 & 0.0861 & 0.995 \\
\hline $\mathbf{1 2}$ & 0.427 & 0.0841 & 3.92 & 0.231 & 0.974 \\
\hline $\mathbf{1 3}$ & 0.101 & -20.1 & -16.3 & 0.112 & 0.990 \\
\hline $\mathbf{1 4}$ & 0.263 & -6.71 & -2.87 & 0.181 & 0.978 \\
\hline $\mathbf{M e a n}$ & 0.344 & -8.20 & -4.36 & 0.190 & 0.972 \\
\hline $\mathbf{S D}^{\mathbf{f}}$ & 0.329 & 13.03 & 13.03 & 0.088 & 0.026 \\
\hline
\end{tabular}

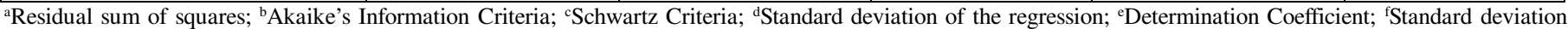

Table 4: Two compartment fits.

\begin{tabular}{|l|l|l|l|l|}
\hline SUBJECT & $\mathbf{V}_{\mathbf{p}} / \mathbf{F F}^{* \mathbf{a}}(\mathbf{L})$ & $\left.\mathbf{k}_{\mathbf{1 2}}^{\mathbf{b}} \mathbf{h}^{-\mathbf{1}}\right)$ & $\mathbf{K}_{\mathrm{el}}{ }^{\mathbf{c}}\left(\mathbf{h}^{-\mathbf{1}}\right)$ & $\mathbf{K}_{\mathbf{2 1}}{ }^{\mathbf{d}}\left(\mathbf{h}^{-\mathbf{1}}\right)$ \\
\hline $\mathbf{1}$ & 26.4 & 0.334 & 0.0375 & 0.146 \\
\hline $\mathbf{2}$ & 53.1 & 0.466 & 0.0368 & 0.786 \\
\hline $\mathbf{3}$ & 51.6 & 0.00428 & 0.0263 & 0.0476 \\
\hline $\mathbf{4}$ & 39.4 & 0.248 & 0.0404 & 0.210 \\
\hline $\mathbf{5}$ & 56.5 & 0.100 & 0.0304 & 0.167 \\
\hline $\mathbf{6}$ & 60.2 & 0.133 & 0.0388 & 0.0846 \\
\hline $\mathbf{7}$ & 46.9 & 0.0418 & 0.0322 & 0.144 \\
\hline $\mathbf{8}$ & 41.1 & 0.585 & 0.0294 & 0.725 \\
\hline $\mathbf{9}$ & 79.7 & -0.00457 & 0.0190 & 0.0485 \\
\hline $\mathbf{1 0}$ & 73.1 & 0.0153 & 0.0190 & 0.140 \\
\hline $\mathbf{1 1}$ & 41.5 & 0.307 & 0.0424 & 0.395 \\
\hline $\mathbf{1 2}$ & 49.3 & 0.0586 & 0.0252 & 0.219 \\
\hline $\mathbf{1 3}$ & 69.0 & 0.0275 & 0.0279 & 0.0878 \\
\hline $\mathbf{1 4}$ & 68.6 & 0.0137 & 0.0314 & 0.0461 \\
\hline $\mathbf{M e a n}^{\mathbf{S}}$ & 54.0 & 0.166 & 0.0312 & 0.229 \\
\hline $\mathbf{C V}^{\mathbf{e}}$ & 14.9 & 0.191 & 0.0074 & 0.241 \\
\hline
\end{tabular}

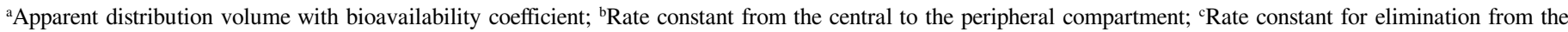
central compartment; ${ }^{\mathrm{d}}$ Rate constant from the peripheral to central compartment; ${ }^{\mathrm{e}}$ Standard deviation; ${ }^{\mathrm{f}}$ Coefficient of variation.

Table 5: Microrate constants for the two compartment open model. 
Citation: Agabeyoglu I, Incecayir T (2009) Pharmacokinetic Modelling of Lamotrigine from Plasma Concentrations in Healthy Volunteers. J Bioanal Biomed 1: 041-045. doi:10.4172/1948-593X.1000009

\begin{tabular}{|c|c|c|c|c|c|c|c|c|c|}
\hline SUBJECT & $\begin{array}{l}\mathbf{t}_{1 / 2}{ }^{2} \\
\text { (h) }\end{array}$ & $\underset{\text { (h) }}{\mathbf{M R T}^{\mathbf{b}}}$ & (h) & $\underset{(\mu \mathrm{g} / \mathrm{mL})}{\mathrm{C}_{\max } \mathrm{d}}$ & $\underset{(\mu \mathrm{g} . \mathrm{h} / \mathrm{mL})}{\mathbf{A U C}}$ & $\begin{array}{l}\mathrm{CI}^{\mathbf{f}} \\
(\mathrm{L} / \mathrm{h})\end{array}$ & $\begin{array}{l}\mathbf{V}_{\text {darea }}{ }^{g} \\
\text { L) }\end{array}$ & $\underbrace{\mathbf{d s s}^{\mathrm{h}}}_{(L)}$ & 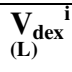 \\
\hline 1 & 64.3 & 96.5 & 2.47 & 3.51 & 198 & 1.01 & 92.9 & 87.0 & 97.1 \\
\hline 2 & 30.3 & 45.2 & 1.58 & 2.38 & 100 & 1.97 & 86.3 & 84.5 & 86.4 \\
\hline 3 & 30.8 & 62.9 & 2.10 & 3.57 & 144 & 1.37 & 60.9 & 56.2 & 68.2 \\
\hline 4 & 39.3 & 60.7 & 3.09 & 2.62 & 123 & 1.61 & 91.3 & 86.0 & 95.0 \\
\hline 5 & 38.1 & 59.0 & 1.35 & 2.95 & 114 & 1.73 & 95.3 & 90.3 & 99.0 \\
\hline 6 & 51.2 & 78.7 & 1.86 & 2.42 & 83.8 & 2.36 & 174 & 155 & 194 \\
\hline 7 & 29.0 & 47.2 & 1.16 & 3.85 & 130 & 1.53 & 63.9 & 60.5 & 66.5 \\
\hline 8 & 43.1 & 63.5 & 1.35 & 2.90 & 163 & 1.22 & 75.6 & 74.2 & 75.7 \\
\hline 9 & 30.0 & 69.7 & 5.43 & 2.27 & 130 & 1.53 & 66.0 & 72.2 & 52.3 \\
\hline 10 & 42.8 & 70.2 & 1.42 & 2.56 & 141 & 1.40 & 86.6 & 83.8 & 88.1 \\
\hline 11 & 29.8 & 45.6 & 2.44 & 2.76 & 111 & 1.78 & 76.4 & 73.7 & 77.8 \\
\hline 12 & 35.6 & 55.4 & 1.82 & 3.48 & 158 & 1.26 & 64.4 & 62.5 & 65.2 \\
\hline 13 & 34.9 & 58.8 & 1.07 & 2.68 & 102 & 1.94 & 98.0 & 90.7 & 105 \\
\hline 14 & 33.9 & 63.2 & 1.05 & 2.72 & 90.9 & 2.18 & 106 & 89.0 & 135 \\
\hline Mean & 38.1 & 62.6 & 2.01 & 2.91 & 128 & 1.63 & 88.5 & 83.2 & 93.2 \\
\hline $\mathbf{S D}^{\mathbf{j}}$ & 9.9 & 13.7 & 1.15 & 0.50 & 31 & 0.39 & 28.6 & 23.6 & 35.6 \\
\hline CV\% ${ }^{k}$ & 26.0 & 21.8 & 57.3 & 17.2 & 24.4 & 23.6 & 32.4 & 28.4 & 38.2 \\
\hline
\end{tabular}

${ }^{\mathrm{a} B i o l o g i c a l}$ half-life; ${ }^{\mathrm{b}}$ Mean Residence Time; ${ }^{\mathrm{c}}$ Estimated time to reach maximum plasma concentration; ${ }^{\mathrm{d}}$ Estimated maximum plasma concentration; ${ }^{\mathrm{e}}$ Area under the curve to infinity; ${ }^{\mathrm{f}}$ Systemic clearance; ${ }^{\mathrm{g}}$ Apparent volume of distribution from area; ${ }^{\mathrm{h}}$ Apparent volume of distribution at steady state; ${ }^{\mathrm{i}}$ Apparent volume of distribution for I.V.; ${ }^{j}$ Standard deviation; ${ }^{k}$ Coefficient of variation.

Table 6: Other pharmacokinetic parameters flor the two compartment open model.

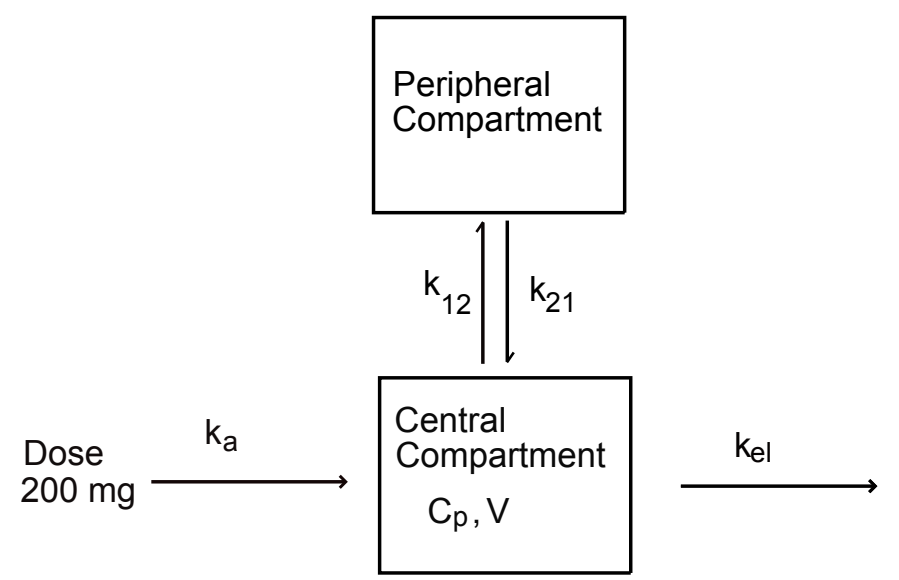

Figure 2: The two compartmental open model of lamotrigine in healthy volunteers $\left(\mathrm{C}_{\mathrm{p}}\right.$ : Plasma concentration $(\mu \mathrm{g} / \mathrm{mL}), \mathrm{V}$ : Apparent distribution volume $(\mathrm{L})$, $\mathrm{k}_{\mathrm{a}}$ : Absorption rate const. $\left(\mathrm{h}^{-1}\right), \mathrm{k}_{\mathrm{el}}$ : Rate constant for elimination from the central compartment $\left(\mathrm{h}^{-1}\right), \mathrm{k}_{12}$ : Rate constant from the central to the peripheral compartment $\left(\mathrm{h}^{-1}\right), \mathrm{k}_{21}$ : Rate constant from the peripheral to central compartment $\left.\left(\mathrm{h}^{-1}\right)\right)$.

hours after the last dose. The concentration of lamotrigine in the brain was higher than the unbound concentration in plasma. On the other hand, concentrations of lamotrigine glucuronide were very low in the brain. On the basis of this result, the good transport of lamotrigine to the brain might explain the data obeying two compartment open model in the present study. Moreover, brain seems to play a role as a peripheral compartment in the two-comparment open model of lamotrigine, which is needed to be proven in future researches.

Previous investigations (Btaiche et al., 1995; Perucca, 1999) in healthy individuals demonstrated that lamotrigine is rapidly absorbed from the gastrointestinal tract. After an oral dose $C_{\max }$ occurs within 1 to 3 hours. This study also showed that absorption of lamotrigine appeared rapid with a $\mathrm{t}_{\max }$ of $2.0 \mathrm{~h}$.

The biological half-life $\left(\mathrm{t}_{1 / 2}\right)$ of lamotrigine was approximately $38 \mathrm{~h}$, which is longer than those reported as 24.1 to $31.2 \mathrm{~h}$ following single oral doses in healthy adults by other researchers
(Yuen et al., 1987; Cohen et al., 1987; Goa et al., 1993). Mean residence time (MRT) of lamotrigine after oral administration, was $62.6 \pm 13.7 \mathrm{~h}$. It was shown that long $\mathrm{t}_{1 / 2}$ and MRT allows once or twice-daily administration of lamotrigine, which has been already used in this dosage regimen in clinical situations. Yau et al., (1991) indicated the dose proportionality of lamotrigine at single oral doses of 50, 200, $400 \mathrm{mg}$ in 20 subjects. The area under the curve of concentration versus time (AUC) for $200 \mathrm{mg}$ dose was $109.4 \pm 36.6 \mu \mathrm{g} . \mathrm{h} / \mathrm{mL}$, which is very close to the AUC value of $128 \pm 31 \mu \mathrm{g} . \mathrm{h} / \mathrm{mL}$ found in the present study.

Systemic clearance $(\mathrm{Cl})$ of $1.63 \pm 0.39 \mathrm{~L} / \mathrm{h}$ and apparent volume of distribution $\left(\mathrm{V}_{\text {darea }}\right)$ of $88.5 \pm 28.6 \mathrm{~L}$ found in this study are comparable to the others reported by most investigators (Yuen et al., 1987; Cohen et al., 1987; Goa et al., 1993; Elwes et al., 1996). No lag time was demonstrated in this study. As a result, it is known that lamotrigine is well absorbed; there is negligible first pass effect and bioavailability is virtually $100 \%$ (Yuen et al., 1987; Gram, 1996).

Researchers have conducted several investigations on the pharmacokinetics of single and multiple doses of lamotrigine, influence of age, comedication, and disease state on lamotrigine pharmacokinetics in both healthy individuals and patients. However, the present study conducted in healthy volunteers receiving single oral dose of lamotrigine, approaches to the pharmacokinetics of lamotrigine in a different perspective of mathematical modelling.

Overall, on the basis of the detailed compartmental analysis, the results of this single dose study demonstrated that oral lamotrigine tablets obey two compartment open model with rapid absorption and a relatively long half life.

\section{Acknowledgement}

This study was supported by the research grant (02/2003-18) from Gazi University, Ankara, Turkey.

\section{References}

1. Brown RD, Manno JE (1978) ESTRIP, a BASIC computer program for J Bioanal Biomed 


\section{Journal of Bioanalysis \& Biomedicine - Open Access JBABM/Vol.1 Issue 1}

obtaining initial polyexponential parameter estimates. J Pharm Sci 67: 16871691. »CrossRef » PubMed » Google Scholar

2. Btaiche IF, Woster PS (1995) Gabapentin and lamotrigine: novel antiepileptic drugs. Am J Health Syst Pharm 52: 61-69. » CrossRef » PubMed » Google Scholar

3. Castel-Branco M, Lebre V, Falcão A, Figueiredo I, Caramona M (2003) Relationship between plasma and brain levels and the anticonvulsant effect of lamotrigine in rats. Eur J Pharmacol 482: 163-168. » CrossRef » PubMed » Google Scholar

4. Cohen AF, Land GS, Breimer DD, Yuen WC, Winton C, et al. (1987) Lamotrigine, a new anticonvulsant: pharmacokinetics in normal humans. Clin Pharmacol Ther 42: 535-541. » CrossRef » PubMed » Google Scholar

5. Elwes RDC, Binnie CD (1996) Clinical pharmacokinetics of newer antiepileptic drugs-lamotrigine, vigabatrin, gabapentin and oxcarbazepine. Clin Pharmacokinet 30: 403-415. » CrossRef » PubMed » Google Scholar

6. Frank LM, Enlow T, Holmes GL, Manasco P, Concannon S, et al. (1999) Lamictal (lamotrigine) monotherapy for typical absence seizures in children. Epilepsia 40: 973-979. »CrossRef » PubMed » Google Scholar

7. Garnett WR (1997) Lamotrigine: Pharmacokinetics. J Child Neurol 12: S10S15. »CrossRef » PubMed » Google Scholar

8. Goa KL, Ross SR, Chrisp P (1993) Lamotrigine: a review of its pharmacological properties and clinical efficacy in epilepsy. Drugs 46: 152-176. » CrossRef » PubMed » Google Scholar

9. Goldsmith DR, Wagstaff AJ, Ibbotson T, Perry CM (2003) Lamotrigine: A review of its use in bipolar disorder. Drugs 63: 2029-2050. »CrossRef » PubMed » Google Scholar

10. Gram L (1996) Pharmacokinetics of new antiepileptic drugs. Epilepsia 37: S12-S16. »CrossRef » PubMed » Google Scholar
11. Incecayir T, Agabeyoglu I, Gucuyener K (2007) Comparison of plasma and saliva concentrations of lamotrigine in healthy volunteers. Arzneimittelforschung 57: 517-521. »CrossRef » PubMed » Google Scholar

12. LaRoche SM (2007) A new look at the second-generation antiepileptic drugs: a decade of experience. Neurologist 13: 133-139. » CrossRef » PubMed » Google Scholar

13. Motte J, Trevathan E, Arvidsson JF, Barrera MN, Mullens EL, et al. (1997) Lamotrigine for generalized seizures associated with the lennox-gastaut syndrome. N Engl J Med 337: 1807-1812. »CrossRef » PubMed » Google Scholar

14. Perucca E (1996) The new generation of antiepileptic drugs: advantages and disadvantages. Br J Clin Pharmacol 42: 531-543. »CrossRef » PubMed » Google Scholar

15. Perucca E (1999) The clinical pharmacokinetics of the new antiepileptic drugs. Epilepsia 40: S7-S13. »CrossRef » PubMed » Google Scholar

16. Ramsay RE, Pellock JM, Garnett WR, Sanchez RM, Valakas AM, et al. (1991) Pharmacokinetics and safety of lamotrigine $\left(\right.$ Lamictal $\left.{ }^{\circledR}\right)$ in patients with epilepsy. Epilepsy Res 10: 191-200. »CrossRef » PubMed » Google Scholar

17. Stefan H, Feuerstein TJ (2007) Novel anticonvulsant drugs. Pharmacol Ther 113: 165-183. »CrossRef » PubMed » Google Scholar

18. Wagner JG (1979) Fundamentals of Clinical Pharmacokinetics. 2nd ed Hamilton, Illinois. »CrossRef » PubMed » Google Scholar

19. Yau MK, Garnett WR, Wargin WA, Pellock JM (1991) A single dose, dose proportionality, and bioequivalence study of lamotrigine in normal volunteers. Epilepsia 32: 3-8. » CrossRef » PubMed » Google Scholar

20. Yuen WC, Peck AW (1987) Lamotrigine pharmacokinetics: oral and I.V infusion in man. Epilepsia 28: 582. » CrossRef » PubMed » Google Scholar 